\title{
El uso de ácido fólico podría prevenir accidentes cerebrovasculares en adultos con hipertensión arterial
}

Use of folic acid could prevent strokes among adults with hypertension

Huo Y, y col. JAMA. 2015;313(13):1325-35.

\section{Objetivos}

Comparar la efectividad entre el tratamiento con enalapril sólo y la asociación de enalapril con ácido fólico en la reducción de la incidencia de eventos cerebrovasculares (ACV) en pacientes hipertensos en China.

\section{Diseño, lugar y pacientes}

Ensayo clínico aleatorizado, doble-ciego. Fue realizado entre Mayo de 2008 y Agosto de 2013 en 32 comunidades de dos provincias de China. Participaron 20.702 adultos con hipertensión arterial sin antecedentes de ACV o infarto de miocardio (IAM). Debido a que algunos polimorfismos genéticos de la enzima metiltetrahidrofolato-reductasa pueden reducir su actividad resultando en bajos niveles de folato, los pacientes elegidos fueron estratificados por sus diferentes genotipos (CC, CT y TT).

\section{Intervención}

Cada grupo de pacientes, estratificados según su genotipo, fueron aleatorizados a recibir enalapril $10 \mathrm{mg}$ con ácido fólico $0,8 \mathrm{mg}(\mathrm{n}=10.348)$ o enalapril $10 \mathrm{mg}$ sólo $(n=10.354)$

\section{Medición de resultados principales}

El objetivo primario fue la aparición del primer evento cerebrovascular. Los objetivos secundarios fueron la incidencia de ACV isquémico, ACV hemorrágico, IAM, eventos cardiovasculares combinados y mortalidad total.

\section{Resultados primarios}

Luego de 4,5 años de seguimiento, el estudio fue terminado de forma prematura debido a que se observó que el grupo tratado con enalapril + ácido fólico tuvo una reducción significativa del riesgo de presentar un primer ACV. Ver resultados en tabla 1.

Por otro lado, no se observaron diferencias entre ambos grupos en el riesgo de presentar un ACV hemorrágico, IAM y mortalidad total, así como tampoco en la incidencia de efectos adversos.

Tabla 1: Resultados principales en ambos grupos

\begin{tabular}{c|c|c|c|c} 
& $\begin{array}{c}\text { Enalapril + ácido fólico } \\
\mathbf{N = 1 0 . 3 4 8}\end{array}$ & $\begin{array}{c}\text { Enalapril } \\
\mathbf{N = 1 0 . 3 5 4}\end{array}$ & $\begin{array}{c}\text { Hazard ratio } \\
\text { (IC 95\%) }\end{array}$ & $\begin{array}{c}\text { NNT } \\
\text { (IC 95\%) }\end{array}$ \\
\hline ACV (\%) & 2,7 & 3,4 & $0,79(0,68$ a 0,93) & $143(83$ a 500) \\
\hline ACV isquémico (\%) & 2,2 & 2,8 & $0,76(0,64$ a 0,91) & 167 (100 a 500) \\
\hline Eventos cardiovasculares combinados (\%) & 3,1 & 3,9 & $0,80(0,69 \mathrm{a} 0,92)$ & 124 (77 a 333) \\
\hline
\end{tabular}

NNT: número necesario a tratar.

\section{Conclusion}

En adultos hipertensos sin antecedentes de ACV o IAM en China, la combinación de enalapril con ácido fólico redujo de forma significativa el riesgo de presentar un ACV comparado con enalapril sólo. Estos hallazgos coinciden con los beneficios observados previamente con el uso de ácido fólico en adultos

\section{Comentario}

El efecto de la suplementación con ácido fólico en la enfermedad cardiovascular es motivo de debate desde hace varios años. Los posibles beneficios de esta estrategia son controversiales. Si bien en varios estudios obsenvacionales se ha visto una relación entre los bajos niveles de folato y el riesgo de padecer un evento cardiovascular-2, este efecto no ha podido demostrarse en estudios aleatorizados en prevención secundaria ${ }^{3-4}$. Además, hasta ahora no se había realizado ningún estudio en prevención primaria. Este estudio fue diseñado cuidadosamente y ha tenido en cuenta los polimorfismos genéticos que pueden llevar a diferencias en los resultados. Fue terminado prematuramente por el Comité de seguridad debido a la observación de una reducción del $21 \%$ del riesgo de ACV en el grupo con ácido fólico. Adicionalmente, se observó un mayor efecto, aunque no significativo en aquellos con niveles bajos de folato al inicio. Este último hallazgo podría explicar los pocos resultados obtenidos en los estudios previos ya que fueron realizados en otras poblaciones, como la americana, donde la implementación de políticas como la fortificación de granos con ácido fólico ha reducido la incidencia de bajos niveles de folato en la población. En Argentina, los datos sobre el consumo de ácido fólico en adultos están eva-luados sólo en mujeres en edad fértil y embarazadas, donde se observa que un $23,1 \%$ y $25,4 \%$ de esta población respectivamente presenta una ingesta menor a la recomendada ${ }^{5}$. Estos datos son previos a la ley 25.630 , vigente desde 2003 que exige que todas las harinas para fabricación de pan estén suplementadas con ácido fólico pero no tenemos datos actuales que nos permitan evaluar la efectividad de la implementación de esta política.

\section{Conclusiones del comentador}

En individuos hipertensos, sin enfermedad cardiovascular, provenientes de poblaciones con bajos niveles de folato, la suplementación con ácido fólico ha demostrado reducir de forma significativa el riesgo de presentar un ACV. Estos resultados deberían replicarse en otras poblaciones con déficits en los niveles basales de folato para poder realizar una recomendación. Por último, se debería comenzar a debatir sobre la fortificación de alimentos con ácido fólico en todas las poblaciones con bajo consumo de alimentos ricos en éste. Esta estrategia es segura, de bajo costo y presenta beneficios adicionales como la reducción de defectos del tubo neural.

María Florencia Decarlini [ Servicio de Medicina Familiar y Comunitaria, Hospital Italiano de Buenos Aires. maria.decarlini@ hiba.org.ar ] Decarlini MF. El uso de ácido fólico podría prevenir accidentes cerebrovasculares en adultos con hipertensión arterial. Evid Act Pract Ambul. 2016 ;19(2)41. Abr-Jun. Comentado de: Huo Y, y col. Efficacy of folic acid therapy in primary prevention of stroke among adults with hypertension in China: the CSPPT randomized clinical trial. JAMA. 2015;313(13):1325-35. PMID: 25771069

Referencias

1. Stampfer MJ, y col. A prospective study of plasma homocysteine and risk of myocardial infartion in US physicians. JAMA 1992; 268(7): 877-881.

2. Morrison HI, y col. Serum folate and risk of fatal coronary heart disease. JAMA. 1996; 275(24): 1893-1896.

3. VITATOPS Trial Study Group. B vitamins in patients with recent transient ischaemic attack or stroke in the vitamins to Prevent Strole trial. Lancet Neurol. 2010; 9(9): 855-865. 4. Toole JF, y col. Lowering homocysteine in patients with ischemic stroke to prevent recurrent stroke, myocardial infarction abd death. JAMA. 2004; 291(5): 565-575. 5. Ministerio de Salud de la Nación. Encuesta Nacional de Nutrición y Salud. Documento de resultados. Buenos Aires, Argentina: Ministerio de la Nación; 2007. Disponible en URL: http://www.msal.gob.ar/images/stories/bes/graficos/0000000257cnt-a08-ennys-documento-de-resultados-2007.pdf (último acceso julio 2016). 